Note: This is a draft of a paper being submitted for publication. Contents of this paper should not be quoted nor referred to without permission of the authors.

[To be presented at the International Conference ${ }_{\text {on }}$ Ion Beam Modification of Materials, Budapest, Hungary, 4-3 September 1978]

ELECTRICAL CHARACTERISTICS OF ION-IMPLANTED LASER-ANNEALED SILICON

R. T. Young, J. Narayan, C. W. White, R. F. Wood, J. W. Cleland and R. D. Westbrook, and P. M. Mooney

By acceptance of this article, the This cepert wis prepsred as an dicount if work spernsurad by the Umied Siates Craverniment. Nethet the United Siates nor the L'nited Siales nepattritem of theit Energ, nut any of thetr employees, nin aly of theit

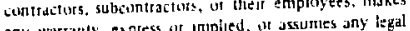
any warranty, express of implied, an jssumes iny iegal liability or tesponsibutry for the acediacy.conmpieteness or usefulness ot any miorsostion, appasatus, priduct or process dischised. or ic presen publisher or recipient acknowledges infringe prisutefy cowned rights.

the U.S. Government's right to

retain a nonexclusive, royaity.free

license in and to any copyright

covering the article.

SOLID STATE DIVISION

OAK RIDGE NATIONAL LABORATORY

Operated by

UNION CARBIDE CORPORATION

for the

UNITED STATES DEPARTMENT OF ENERGY

Oak Ridge, Tennessee

August 1978 


\section{ELECTRICAL CHARACTERISTICS OF ION-IMPLANTED LASER-ANNEALED SILICON *}

R. T. Young, J. Narayan, C. W. White, R. F. Wood, J. W. Cleland and R. D. Westbrook

Solid State Division, Oak Ridge National Laboratory,

Oak Ridge, Tennessee 37830

P. M. Mooney ${ }^{\dagger}$

Institute for the Study of Defects in Solids

Physics Department, State University of New York at Albany

Albany, New York 12222

In the past year, many experiments have been conducted to study the use of laser radiation for the removal of lattice damage produced in $\mathrm{Si}$ by ion implancation processes. ${ }^{1-5}$ Detailed results concerning the use of a Qswitched ruby laser to remove lattice damage and an understanding of the associated annealing mechanism have been reported by us in previous publications ${ }^{1,5,6}$ for $B$ (the most widely used p-type dopant) implanted $S i$. In this paper, we present the results of electrical measurements on $S i$ implanted with n-type dopants such as $\mathrm{P}$ and As and laser annealed.

We have used van der Pauw measurements to determine the sheet resistivity and sheet carrier concentration of various implanted samples after thermal and laser annealing. The results have been correlated with transmission electron microscopy (TEM) studies. In order to examine the feasibility of the method for device fabrication, mesa diodes were fabricated and tested. Laser-induced defects were also studied by deep level transient spectroscopy (DLTS) to investigate any effect of laser-induced damage on device performance.

Laser annealing was performed in air with a Q-switched ruby laser (puise duration $\sim 50 \mathrm{~ns}$ ) operating in a multimode condition. Implants (80 KeV

\footnotetext{
* Research sponsored in part by the Division of Materials Sciences, U. S. Department of Energy under contract W-7405-eng-26 with the Union Carbide Corporation and ONR contract N00014-75-C-0919.

TPermanent Address: Department of Physics and Astronomy, Vassar Coillege, Poughkeepsie, New York 12601.
} 
and $100 \mathrm{KeV}$ ) were carried out at room temperature to doses in the range of $1 \times 10^{14}$ to $2 \times 10^{16} \mathrm{~cm}^{-2}$ on $5-10 \mathrm{ohm}-\mathrm{cm} \mathrm{B}$-doped (100) Si samples.

The threshold laser energy density for complete annealing of the implanted layer was found to be dependent on such parameters as the implant energy and species. Figure 1 shows the sheet resistivity as a function of the laser energy density for As and B implanted Si samples. The threshold energy density for the recovery of electrical activity for the As implanted $S i$ is lower than for the B implanted Si. Since the damage profile of $100 \mathrm{KeV}$ As implanted $\mathrm{Si}$ is shallower than that of $35 \mathrm{KeV} \mathrm{B} \mathrm{im-}$ planted Si, 7 this result was anticipated because, as predicted by Wang et $a z^{8}$ the annealing threshold is expected to be closely related to the depth of the disordered region. The results of the melt front profile calculations in ref. 8 suggest that the annealing mechanism is governed by liquid phase epitaxial regrowth. The regrowth of the damaged layer is dependent on the melting depth and duration and these are dependent on the incident photon energy density for a fixed pulse duration.

Figures $2 \mathrm{a}$ and $2 \mathrm{~b}$ are plots of the measured free carrier concentrations in silicon samples implanted with various doses of ${ }^{31} \mathrm{P}(80 \mathrm{keV})$ and ${ }^{75_{\mathrm{As}}}(100$ $\mathrm{KeV})$ and subsequently subjected to thermal and laser annealing $\left(1.5 \mathrm{~J} / \mathrm{cm}^{2}\right)$. Since recrystallization of amorphous $\mathrm{Si}$ occurs at $\sim 600^{\circ} \mathrm{C}$, the thermal annealing results indicate that all samples except the lowest dose $P$ implanted one in Fig. 2a are amorphous after implantation. However, in the high dose samples, the recovery of the electrical activity at $600^{\circ} \mathrm{C}$ is rather poor. Transmission electron microscopy investigation of these samples indicated poor crystallinity. This fact may be related to the high degree of amorphousness after high-dose implantations. Ohdomari et al., 9 in examining Si implanted with $A r$ at various doses, reported that the higher the degree of amorphousness, the worse was the quality of the crystaliinity after recrystallization. On the other hand, in the laser arinealed samples, full recovery of the free carrier concentration was achieved irrespective of the initial state of the amorphousness.

The TEM results in Fig. 3 show that there is no damage in the laser annealed Si samples down to the resolution of the microscope $\sim 10 \mathrm{~A}$. In contrast, lattice imperfections in the form of dislocations or dislocation 
loops remain after thermal annealing at 900 and $1100^{\circ} \mathrm{C}$. These results demonstrate that laser annealing is much more effective in removing lattice damage and restoring electrical activity than is conventional thermal annealing.

In order to investigate the feasibility of laser annealing techniques for device fabrication, mesa diodes (area $\sim 1.1 \times 10^{-3} \mathrm{~cm}^{2}$ ) were formed on various samples. Figure 4 shows a typical forward-biased dark I-V curve of a diode fabricated from an As-implanted laser-annealed Si sample. The $I-V$ characteristics may be fitted to the ideal diode equation $I=I_{0}$ $\left[\exp \left(\frac{q V}{A k t}\right)-1\right]$ by using $A=1.62$ in the voltage range 0.3 to $0.5 \mathrm{~V}$; this indicates that recombination effects are reasonably reduced in the space charge region. Due to excess diode resistance the I-V curve bends away from an $A=1.62$ line beyond $0.5 \mathrm{~V}$. Reverse current measured at $-0.5 \mathrm{~V}$ indicates a low leakage current.

The effect of laser induced defects in $\mathrm{Si}$ was studied by the DLTS technique. Figure 5 shows the DLTS spectrum of an unimplanted, B doped Si control sample irradiated with three laser pulses $\left(E=1.5 \mathrm{~J} \mathrm{~cm}^{-2}\right)$. There is a dominant peak with an energy level at $E_{v}+0.24 \mathrm{eV}$. Depth profile measurements show that the defects are concentrated near the surface, extending into the sample about $10 \mu \mathrm{m}$. A similar though somewhat broader peak with an energy level at $E_{v}+0.22 \mathrm{eV}$ was observed in samples irradiated with a single laser pulse under voltage bias and pulse conditions such that the measured region was from about 1.7 to $2 \mu \mathrm{m}$ in depth. By selecting a deeper region in the $\mathrm{Si}(2$ to $2.5 \mu \mathrm{m})$ an additional peak was observed with an energy level at $E_{v}+0.37 \mathrm{eV}$. In both measurements the trap density was $\approx 1 \times 10^{14} \mathrm{~cm}^{-3}$. Compared to the emitter doping density in a normal device, the density of these trapping centers is so low that their influence on junction characteristic can be neglected; this is confirmed by the good I-V curve shown in Fig. 4.

In conclusion, our results indicate that complete removal of lattice daniage can be achieved by using those laser conditions which give rise to full recovery of electrical activity in the implanted layer, no matter what the degree of amorphousness. The annealing threshold of the laser energy 
density varies with the implanted species and the implantation energy. Diodes with good junction characteristics can be fabricated, and the density of laser-induced defects is so low that they have no significant effect on diode performance.

\section{REFERENCES}

1. R. T. Young, C. W. White, G. J. Clark, J. Narayan, W. H. Christie, M. Murakami, P. W. King and S. D. Kramer, App1. Phys. Lett. 32, 139 (1978) and Russian references contained therein.

2. G. K. Celler, J. M. Poate, and L. C. Kimerling, Appl. Phys. Lett. 32, 464 (1978).

3. A. Gat, J. F. Gibbons, T. J. Magee, J. Peng, V. Deline, P. Williams and C. A. Evans, Jr., Appl. Phys. Lett. 32, 276 (1978).

4. G. Foti, S. U. Campisano, E. Rimini, J. Appl. Phys. 49, 2569 (1978).

5. C. W. White, W. H. Christie, R. E. Eby, J. C. Wang, R. T. Young and G. J. Clark, Proceedings of the Topical Conference on Characterization Techniques for Semiconductor Materials and Devices, Seattle, Washington, May 21-26, 1978, in press.

6. R. T. Young, C. W. White, J. Narayan, G. J. Clark and W. H. Christie, Proceedings of the Topical Conference on Characterization Techniques for Semiconductor Materials and Devices, Seattle, Washington, May 2126,1978 , in press.

7. C. W. White, W. H. Christie, P. P. Pronko, B. R. Appleton, S. R. Wilson, R. T. Young, J. W. Wang, R. F. Wood, J. Narayan and C. W. Magee, these proceedings.

8. J. C. Wang, R. F. Wood and P. P. Pronko, Appl. Phys. Lett. (in press).

9. I. Ohdomari, M. Ikeda, H. Yoshimoto, N. Onoda, Y. Tanabe and T. Itoh in Proceedings of the 5th International Conference on Ion Implantation in Semiconduators and other Materials, Boulder, Colorado, August 8-13, 1976, p. 39. 


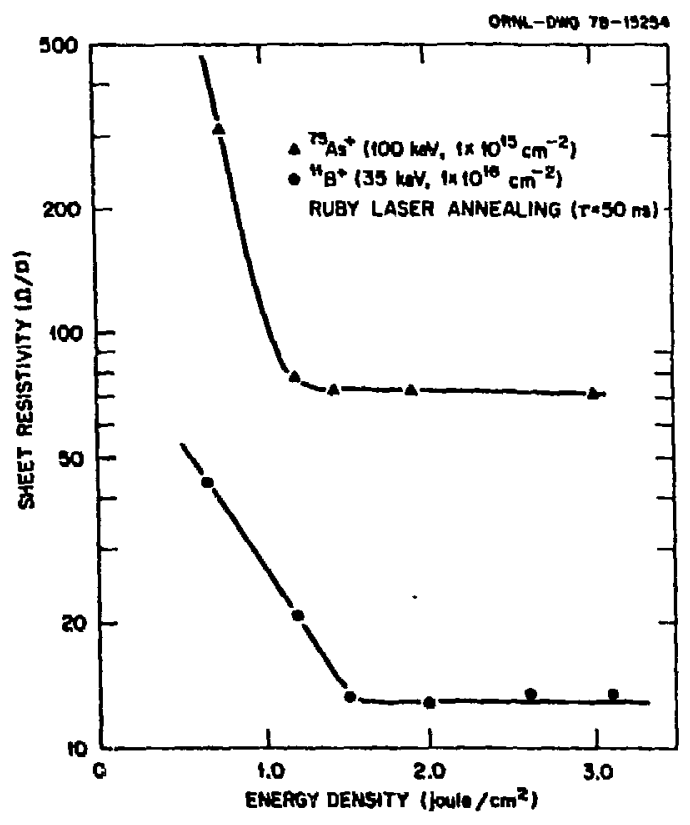

Fig. 1. The recovery of sheet resistivity as a function of laser energy density for $A s(\Delta)$ and $B(B)$ implanted Si.
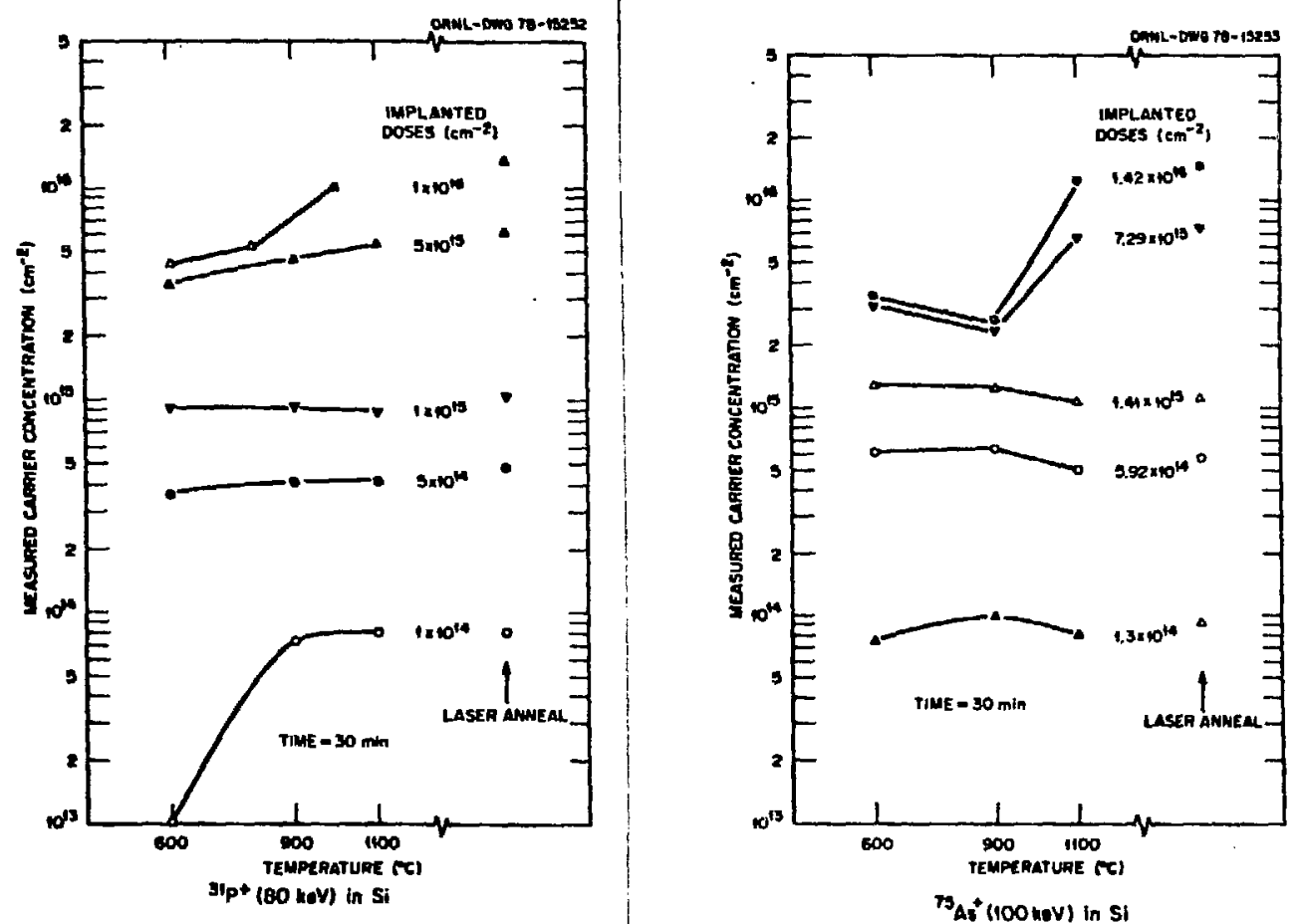

Fig. 2. Sheet carrier density of (a) ${ }^{31} \mathrm{P}$ and (b) ${ }^{75} \mathrm{~A}^{\prime}$; implanted $\mathrm{Si}$ after laser and thermal annealing. 


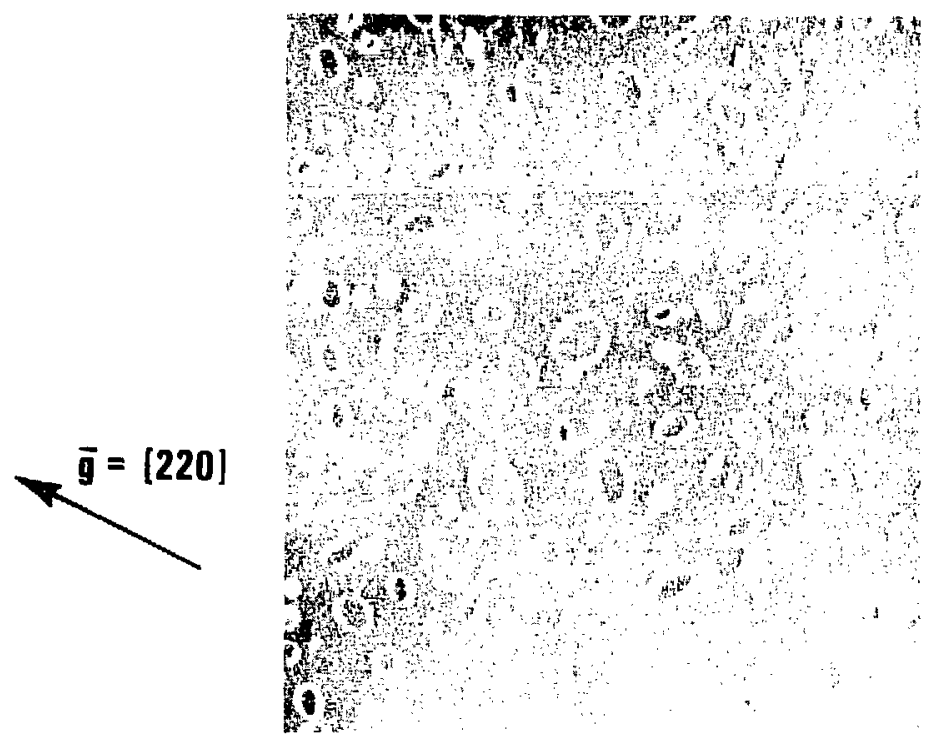

A. Comparison of laser and thermal annealing in $31 \mathrm{p}^{+}$implanted ( $80 \mathrm{KV}$, dose $1.0 \times 10^{15} \mathrm{~cm}^{-2}$ ) silicon: a) Laser annealed, bright field; b) Weak beam electron micrograph after annealing at $1100^{\circ} \mathrm{C}$ for $30 \mathrm{~min}$. The arrows indicate the directions of diffraction vector [2z0] and their length is $0.3 \mu \mathrm{m}$.

\section{$0.3 \mu$}
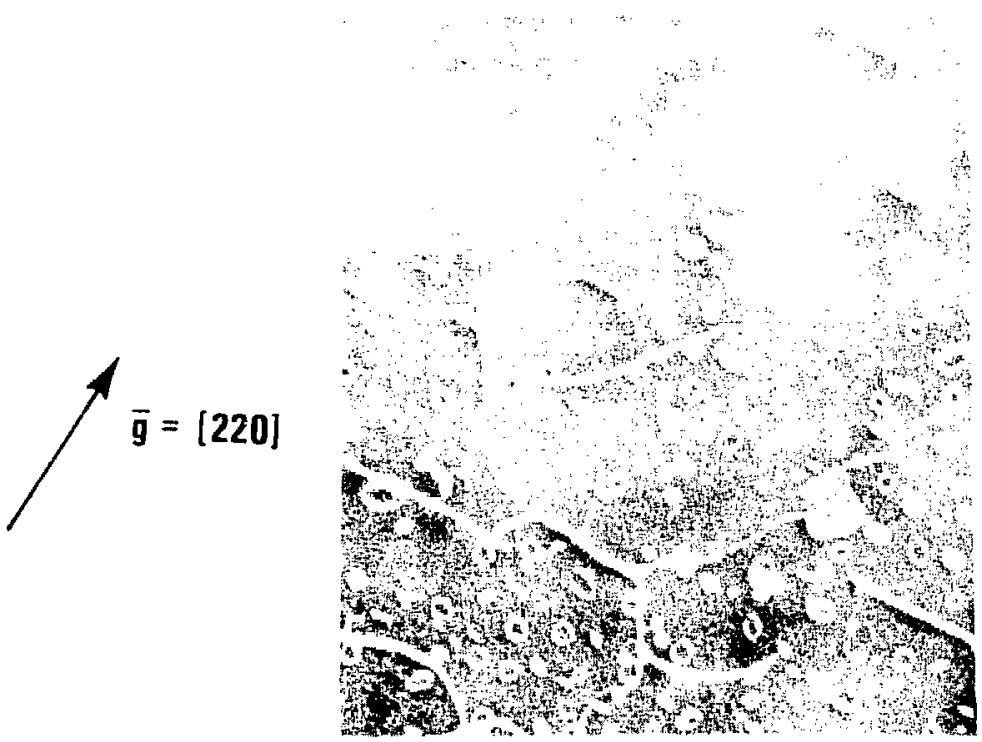

B. Comparison of laser and thermal annealing in arsenic $\left({ }^{75} \mathrm{As}^{+}\right)$ implanted (100 KV, dose $=1.0 \times 10^{16} \mathrm{~cm}^{-2}$ ) silicon: a) Laser annealed, bright field; b) Weak beam electron micrograph after thermal annealing at $900^{\circ} \mathrm{C}$ for $30 \mathrm{~min}$.

Fig. 3 

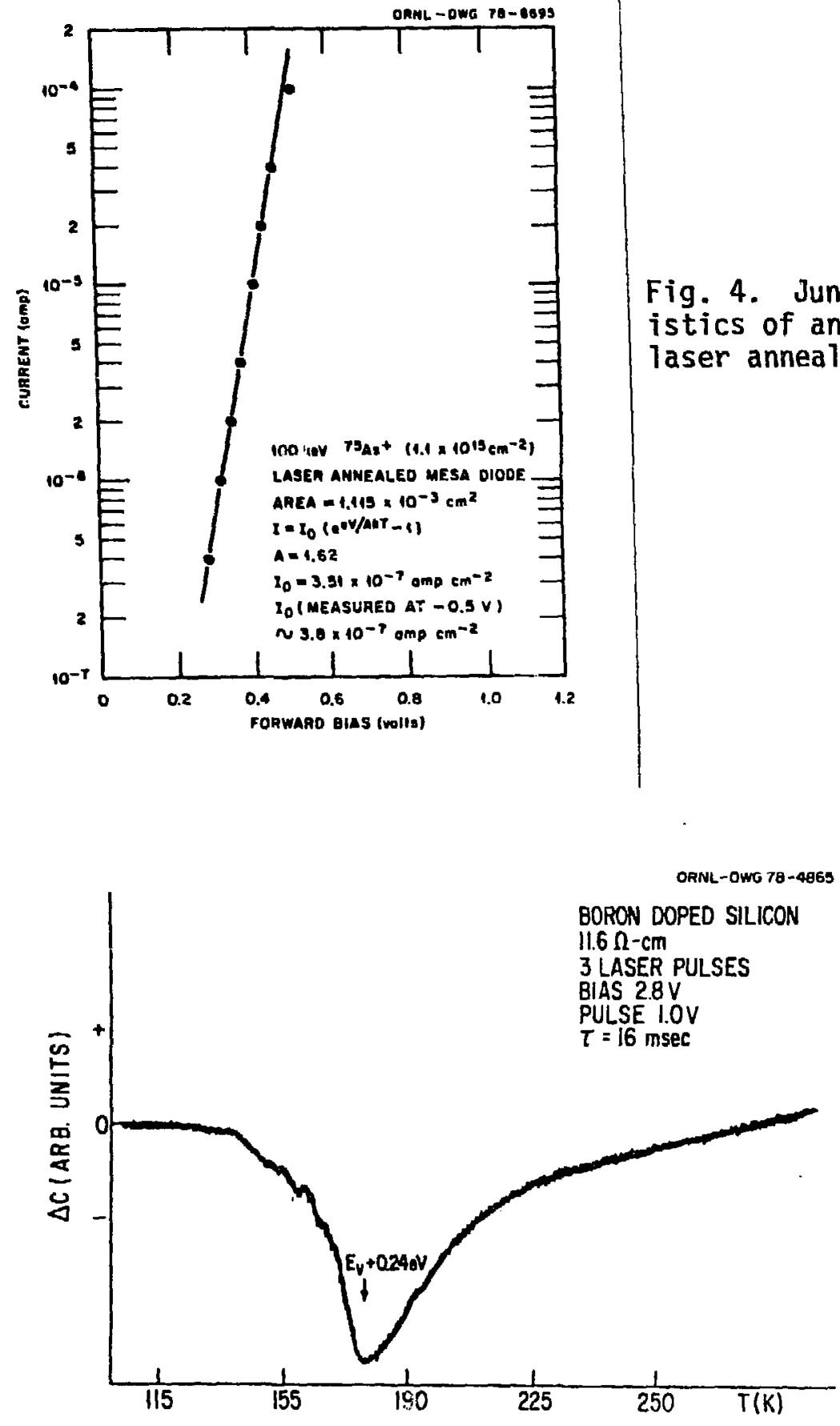

Fig. 4. Junction Characteristics of an As implanted laser annealed mesa diode.

Fig. 5. DLTS spectrum for B doped Si irradiated: with three laser pulses ( $E=1.5 \mathrm{~J} \mathrm{~cm}^{-2}$, $\tau \sim 50 \mathrm{~ns})$. 